

GESTÃO

PRODƯCุÃO

ISSN 0104-530X (Print)

ISSN 1806-9649 (Online)

ERRATUM

\title{
ERRATUM: Linear combination of chi-squares for multinomial process monitoring
}

Ramzi Talmoudi ${ }^{1}$ (D), Ali Achouri² (D), Hassen Taleb²

${ }^{1}$ University of Carthage, LR18ES48 ENVIE Laboratory, Faculté des Sciences Economiques et de Gestion de Nabeul,

Tunisia. E-mail: ramzi.telmoudi@fsegn.u-carthage.tn

${ }^{2}$ University of Carthage, ARBRE Laboratory, Tunisia

Due to desktop publishing error the article "Linear combination of chi-squares for multinomial process monitoring" (DOI https://doi.org/10.1590/1806-9649-2021v28e41), published in Gestão \& Produção, 28(3), e41 was published with an error.

On page 1, where the text reads:

ORIGINAL ARTICLE

It should read:

THEMATIC SECTION: STATISTICAL PROCESS MONITORING AND CONTROL

The publisher apologizes for the errors. 